\title{
Peer mentoring for undergraduates in a research-focused diversity initiative
}

Thomas E. Keller, Kay Logan, Jennifer Lindwall, and Caitlyn Beals

\begin{abstract}
To provide multi-dimensional support for undergraduates from traditionally underrepresented backgrounds who aspire to careers in research, the BUILD EXITO project, part of a major NIHfunded diversity initiative, matches each scholar with three mentors: peer mentor (advanced student), career mentor (faculty adviser), and research mentor (research project supervisor). After describing the aims of the diversity initiative, the institutional context of the BUILD EXITO project, and the training program model, this article devotes special attention to the rationale for and implementation of the peer mentoring component within the context of the multi-faceted mentoring model.
\end{abstract}

\section{Keywords}

Peer mentoring, diversity, research training

\section{Introduction}

Building University Infrastructure Leading to Diversity (BUILD) is an NIH-sponsored initiative to promote innovative approaches to research training for undergraduates from backgrounds traditionally underrepresented in the biomedical and behavioral sciences. The ultimate goal is for these students to diversify the NIH-funded research workforce of the future (Valantine \& Collins, 2015). Mounting evidence suggests the importance of diverse perspectives for enhancing the quality of research, improving the provision of health care, and addressing pervasive health disparities (McGee, Saran \& Krulwich, 2012; Mitchell \& Lassiter, 2006; Valantine \& Collins, 2015). Although NIH has a long history of supporting research and training programs for researchers of diverse backgrounds, scholars receiving major NIH research grants still are not representative of the general population (Ginther et al., 2011). The BUILD initiative addresses this challenge by not only supporting student trainees but also developing faculty capacity and institutional infrastructure to "transform the culture and efficacy of biomedical research training and mentoring” (Enhancing the diversity of the NIH-funded workforce, 2016).

The BUILD initiative focuses on primarily undergraduate institutions (including several metropolitan universities) that fit a specific eligibility profile. First, these universities serve relatively high proportions of undergraduates from traditionally underrepresented populations, including racial and ethnic minority students, students with disabilities, and students with histories of severe social and economic disadvantage. Second, these universities have limited $\mathrm{NIH}$ funding but show the potential to develop greater research capacity. Finally, these universities do not include medical schools but have established partnerships with researchintensive medical centers. Ten institutions meeting these criteria have been awarded BUILD funding to develop and implement sustainable strategies to foster student engagement and 
persistence in the biomedical and behavior sciences. An expectation of NIH is that the funded programs employ approaches shown to influence students in pursuing science career trajectories, such as incorporating research inquiry into coursework (Bangera \& Brownell, 2014; Weaver, Russell \& Wink, 2008), providing meaningful undergraduate research experiences (Hunter, Laursen \& Seymour, 2007; Lopatto, 2007; Russell, Hancock, \& McCullough, 2007) and supporting students through quality mentoring (Wilson et al., 2012; Zaniewski \& Reinholz, 2016). Thus, BUILD faculty development efforts generally aim to support pedagogical innovation to bring lab and field work into courses, increase opportunities for faculty to engage in and publish biomedical research, and provide coaching on the effective mentoring of undergraduate students.

The BUILD initiative is one component of NIH's larger Enhancing Diversity in the NIH-Funded Workforce consortium focusing on scientifically driven approaches to fostering diversity (Valantine \& Collins, 2015). The consortium also includes the National Research Mentoring Network (NRMN), created "to develop best practices for mentoring, provide training opportunities for mentors, and provide networking and professional opportunities for mentees” (DHHS, 2013, p. 4). NRMN provides consultation, curricula, and training to augment the mentoring programs offered by the BUILD program sites. Another organization, the Coordination and Evaluation Center (CEC) at UCLA, was established to provide operational and data coordination and support for the consortium, and to conduct a longitudinal evaluation of the BUILD and NMRN programs. Its goal is to promote a collaborative environment across BUILD sites, NMRN, and NIH and to work closely with BUILD leadership to ensure successful completion of all consortium objectives (Coordination \& Evaluation Center at UCLA, n.d.). To facilitate flexibility and adaptation, BUILD awards are actually cooperative agreements that call for frequent interaction with NIH program officers in the administration of three separate but interlocking funding mechanisms supporting: (a) student trainee financial packages (stipend and tuition remission); (b) research enrichment activities for students; and (c) institutional and faculty development initiatives. As a Common Fund initiative from the NIH Director's office, the BUILD awards support the training of biomedical, behavioral, social, clinical, and translational researchers across a range of disciplines and topics as broad as those funded by all NIH branches.

\section{BUILD EXITO program}

One of the BUILD grantees is the EXITO project (see Richardson et al., 2016). EXITO means "success" in Spanish and stands for Enhancing Cross-disciplinary Infrastructure and Training at Oregon. The BUILD EXITO project represents a partnership of eleven institutions in geographically diverse locations. The primary grantee is Portland State University (PSU), a major public urban university with a historic emphasis on accessibility and the largest and most diverse student enrollment in the state of Oregon. The research-intensive partner is Oregon Health \& Science University (OHSU), a comprehensive academic health center located just miles from PSU that features patient care, medical education, and an extensive world-class research portfolio. To provide integrated educational pathways for students, the BUILD EXITO network also incorporates four community colleges that contribute a large number of transfer students to PSU. These are Chemeketa Community College (Salem, OR), Clackamas Community College (Oregon City, OR), Clark College (Vancouver, WA), and Portland Community College (Portland, OR). In addition, BUILD EXITO includes several 2-year and 4- 
year institutional partners that span the Pacific Rim region: American Samoa Community College, Northern Marianas College, University of Alaska Anchorage, University of Hawaii, and University of Guam.

The institutional home for BUILD EXITO at PSU is the Center for Interdisciplinary Mentoring Research (CIMR), a university-level center under the auspices of the Office of Research and Strategic Partnerships. CIMR was established in 2010 with seed funding from the Provost awarded through a campus-wide RFP designed to identify a cross-disciplinary theme that could organize existing faculty strengths to pursue external funding. CIMR addresses mentoring across the lifespan via innovative and rigorous research, education and knowledge transfer, and partnerships with organizations providing services. The university investment in CIMR provided the existing faculty network, staffing, and infrastructure to facilitate an application to NIH for a BUILD planning grant. A core team of four CIMR faculty and staff submitted the planning grant proposal. This team consisted of: 1) the Director of the PSU School of Community Health and Director of an NIH-sponsored Bridges to Baccalaureate training grant, who identified the RFA and became the Principal Investigator; 2) a Professor in the PSU School of Social Work and Director of CIMR; 3) the Chair of Bioinformatics, Assistant Dean for Admissions in the Medical School, and Director of Education and Career Development for the Oregon Clinical and Translational Institute at OHSU; and 4) the Center Coordinator for CIMR. Receipt of the sixmonth planning grant permitted this team to develop and refine the program model, recruit collaborating colleagues in additional fields, identify and reach out to prospective partner institutions, and prepare the extremely lengthy proposal that ultimately resulted in the $\$ 23.7 \mathrm{M}$, 5year BUILD award.

The scholar training model for the BUILD EXITO program offers an integrated set of experiences along a pathway leading to graduate education and careers in research. Employing a cohort-building approach, groups of eligible students are recruited and selected through a competitive application process during the spring of their first year in college and continue in the program through graduation with a bachelor's degree (either transferring from 2-year partner institutions to PSU or maintaining enrollment at original 4-year partner institution). In addition to providing opportunities for learning the concepts and developing the skills necessary to become a scientist, the program addresses the multiple psychological, social, cultural, and financial factors that often pose barriers for students from traditionally underrepresented backgrounds pursuing biomedical majors (Gazley et al., 2014; Hurtado et al., 2007).

For example, evidence suggests that academic persistence and success for underrepresented minority students in science is associated with overcoming prejudice and stereotype threat, developing an identity as a scientist, developing a sense of science self-efficacy, having peer social support, and engaging in campus activities and opportunities (Chang, Sharkness, Hurtado \& Newman, 2014; Chemers et al., 2011; Syed, Azimitia \& Cooper, 2011). Consequently, the BUILD EXITO scholar training program focuses on four domains to provide holistic developmental support and promote successful preparation for post-graduate education: (a) supportive environment; (b) enhanced curriculum;(c) research experience; and (d) multi-faceted mentoring.

Supportive Environment. As a model demonstration program, BUILD EXITO works to transform systems within and across partner institutions to better address the personal, social, 
academic, and financial needs of all students, particularly those who have traditionally encountered institutional barriers. For students selected into the program (referred to as EXITO scholars), the program fosters a supportive community of scholars and provides numerous supports at the individual level. The program begins with participating scholars from all partner institutions attending a weeklong orientation at PSU that features a series of activities and events designed to explore and define research interests and build a sense of camaraderie within the cohort. During the academic year, scholars participate in weekly enrichment sessions that cover a range of topics relating to academic success and career development but also provide opportunities for socializing. The EXITO Center at PSU provides an on-campus "home base" for the program and serves as a hub connecting scholars to project staff and advisors, various resources, opportunities to work with peers, and other activities and events that support learning and foster a sense of shared purpose and community. Scholars also are connected with a variety of campus opportunities and services, including research fairs, student groups, cultural centers, tutoring services, and numerous other resources. In addition, EXITO scholars get to work one-toone with an EXITO-specific academic advisor and financial aid advisor who have a special understanding of program expectations and opportunities. Finally, it is worth noting that the resources available through the BUILD award permit compensation packages for scholars for time spent in EXITO training activities.

Enhanced Curriculum. The BUILD EXITO program features several curricular enhancements to support the development of undergraduates as researchers. BUILD EXITO curriculum development staff work with faculty at each partner institution to support inquiry-based teaching approaches. This joint effort incorporates research projects into selected first year courses to inspire interest in science. After being selected for the program, EXITO scholars take a required gateway course that addresses research methods and the responsible conduct of research. EXITO scholars also participate in summer intensive research experiences with workshop curriculum that sharpens their research skills. In their senior year, EXITO scholars are expected to complete a student-initiated capstone research project or thesis project. In addition, as noted above, EXITO scholars participate in regular enrichment workshops and training seminars throughout their time in the program. BUILD EXITO also works with schools and departments with relevant majors, such as biology, chemistry, psychology, social work, and community health, to support scholars in these disciplines, with a special emphasis on making sure credits and content align for EXITO scholars transferring from partner institutions.

Research Experience. A centerpiece of the BUILD EXITO program is the opportunity for scholars to gain research experience as contributing members of Research Learning Communities (RLCs), headed by leading researchers. EXITO RLCs engage undergraduate students in meaningful research activities on externally-funded, faculty-directed studies across a range of health-related fields (e.g., biomedical, behavioral, social, clinical, and translational research). Though RLCs vary in structure and composition, a typical example includes one or more established principal investigators who have participated in major federal studies and have collaborates with other colleagues, such as faculty co-investigators, fellows, post-docs, and graduate students. EXITO scholars are embedded within these mentor-rich communities in paid internship placements to work as part of the research team. During the summer and academic year, scholars spend concentrated time working to observe, learn, and contribute to important research projects while in their RLCs. 
Multi-faceted Mentoring. BUILD EXITO offers each scholar a convoy of support along the pathway to success. A team of mentors strives to meet the multi-dimensional needs of students from traditionally underrepresented backgrounds embarking on a demanding research-oriented career trajectory. There are three distinct mentoring roles in the BUILD EXITO model, and each reflects a different perspective, has a different set of priorities, and offers a different mix of skills and support. Career mentors are faculty members who offer advice on academic and career planning and goal setting. Peer mentors are advanced students who facilitate connections to campus and help scholars to navigate the student experience. Research mentors work with scholars within their RLC's to teach them skills, supervise their work, and provide feedback about continued growth and development. These mentors are integrated into the student experience at developmentally appropriate stages and provide crucial support on a successful pathway to research. A rationale for this mentoring model and an examination of the special role of peer mentors are presented below.

\section{Rationale for multi-faceted mentoring model}

For EXITO scholars to pursue post-graduate education and become biomedical researchers, they must attain their undergraduate degrees and prepare for future research opportunities. Therefore, the BUILD EXITO program focuses both on educational persistence and on research preparedness. Conceptual models of student persistence and success emphasize the importance of academic integration (adapting to educational environment) and social integration (engaging with others) in student college experiences (Kuh et al., 2006; Reason, 2009). Similarly, research preparedness develops through research integration (participating in research experiences) (Shaw, Holbrook \& Bourke, 2013). Accordingly, the BUILD EXITO program matches each scholar with a set of three mentors who can provide support and guidance in the academic, psycho-social, and research domains by virtue of their roles as faculty, peers, and researchers.

A multi-faceted mentoring model increases the chances of addressing the various factors associated with the success of EXITO scholars. The scholars resemble most undergraduates in having multi-dimensional needs for support, including psychological and emotional support, assistance acquiring academic subject knowledge, guidance on goal-setting and career paths (Nora \& Crisp, 2007). According to Wallace, Abel, and Ropers-Huilman (2000), students benefit from more than one mentor with whom to share their social, cultural, and academic concerns. In similar circumstances, graduate research trainees and early career academics seek out multiple sources of mentoring to meet their distinct functional needs for support (de Janasz \& Sullivan, 2004; Keller et al., 2014). Research from a variety of career settings indicates that having a larger and more diverse constellations of developmental mentoring relationships is associated with greater career satisfaction and success (Higgins \& Thomas, 2001; Packard, Walsh \& Seidenberg, 2004; van Emmerik, 2004). Furthermore, gaining experience with multiple mentors and colleagues can be particularly helpful as team science is increasingly emphasized in research (Guise, Geller, Regensteiner, \& Raymond, 2016).

In the BUILD EXITO model, faculty who serve as career mentors are encouraged to adopt a student-focused orientation. In the process, they establish a relationship characterized by a strong connection, authenticity, commitment, and genuine concern for the scholar (Schreiner, Noel, Anderson, \& Cantwell, 2011). Based on understandings gained through the relationship, the 
nature of mentoring activities, conversations, and assistance can be determined by the circumstances, interests, and goals of the scholar. The mentor can offer a faculty perspective on a range of topics. Most are academic, such as advising about courses and majors, discussing career options, identifying scholarships, or strategizing about study skills. Others could be social, such as resolving roommate conflicts, addressing work-school-family balance, handling a personal crisis, or planning for school breaks (e.g., Kendricks, Nedunuri, \& Arment, 2013). Facultystudent mentoring with this type of multi-purpose orientation has been shown to have positive effects on GPA, credits earned, and retention (Campbell \& Campbell, 1997).

Each EXITO scholar is assigned a primary research mentor when placed in a Research Learning Community. Mentors have been identified as crucial in the success of undergraduate research experiences (Linn, Palmer, Baranger, Gerard \& Stone, 2015). Research mentors provide direct supervision and guidance as EXITO scholars gain first-hand knowledge about designing, conducting, and communicating the research of the RLC. Compared to the student-oriented focus of career mentoring, research mentoring is project-oriented, placing priority on completing tasks necessary for conducting the research. In this respect, the mentoring reflects an apprenticeship in which the mentor instructs the scholar on research protocols and procedures, initially providing clear expectations, guidelines, and orientation to the project. Then, at a later stage, the mentor helps the scholar develop the traits, habits, and perspectives of a scientific researcher (Thiry \& Laursen, 2011). Through frequent contact and joint work on the project, research mentors also help scholars to gain confidence in their research skills and develop a science identity by observing and exploring different research roles (Shanahan, Ackley-Holbrook, Hall, Stewart \& Walkington, 2015).

EXITO peer mentors are advanced undergraduate students, typically seniors, who provide personal support and serve as guides to student life and academic success (e.g., Zaniewski \& Reinholz, 2016). Peer mentors facilitate social integration by helping EXITO scholars connect to campus cultural activities, groups, and programs as well as navigate university services such as housing, financial aid, and recreation. In addition, the peer mentors share personal insights and counsel scholars on how to take best advantage of EXITO courses, resources, and research experiences. The BUILD EXITO peer mentoring program employs a "near-peer" approach, in which a student is matched with a mentor who shares a similar background but already has navigated a pathway to the type of success desired by the mentee (Terrion \& Leonard, 2007). Such a mentor is likely to have strong credibility with the scholar (Hill \& Reddy, 2007). As a role model, the peer mentor provides a concrete example that someone from a similar background can achieve what the scholar aspires to do (Wallace, Abel \& Ropers-Huilman, 2000).

\section{EXITO peer mentor expectations}

Although peer mentors in the BUILD EXITO program are intended to provide psychosocial support and foster social integration in the academic setting, the role is nevertheless multidimensional and responsive to the circumstances of the scholars. Mentoring centers on a personal relationship and to a certain extent is determined by the needs and interests of the individuals involved. For example, research suggests that peer mentors can adopt several different roles, such as coach, advocate, liaison, or friend (Colvin \& Ashman, 2010). Taking a holistic approach in providing support, peer mentors can promote mentee growth in multiple domains, including 
academic skills, career decision-making, connectedness, maturity, health and well-being, and aspirations (Ward, Thomas \& Disch, 2012). Concretely, peer mentors have been shown to help mentees with coursework, organization and time management, campus resources, social issues, stress, and finding employment (Zaniewski \& Reinholz, 2016).

In the BUILD EXITO program, the initial training for peer mentors explicitly notes certain domains in which they might assist their scholars. A listing of these domains with examples of mentoring activities within each was prepared for the initial peer mentor training. Prior to sharing the list, peer mentors did a training activity that involved generating their own ideas about ways in which they might support EXITO scholars. These two lists, presented side-by-side in Table 1, provide a good indication of the expectations for EXITO peer mentors.

Table 1.

Activity Domains for Peer Mentoring

Developed by program staff Developed by peer mentors

Substantive Interests

Discussing research interests, projects, and findings

Talking about disciplines, majors, and/or courses

Networking with researchers and prospective mentors

Discussing professional societies and conferences

General Knowledge and Skills

Working on writing and communication skills Helping with proposals and/or manuscripts

Discussing study habits

Building confidence in research skills and abilities

Student Life (Opportunities, Support, Problem-Solving)

Connecting with campus services and resources

Problem-solving practical issues (e.g. registration, financial aid, transportation)

Discussing balance between school, work, and family

Discussing experiences related to personal background/history (e.g., gender, race, first generation)

Consulting about difficulties with courses, instructors, employers, mentors, etc.
Substantive Interests

New ideas and avenues for exploration

Helping find a field that matches research

interests

Research topics

General Knowledge and Skills

Helping with time management

Helping with prioritizing

Advising on posters and presentations

Helping students learn "strategic sharing"

Learning how to approach faculty

Forming an academic strategy (e.g., study plans)

Advising on what to do if you don't like a class

Helping when scholars don't know how to communicate with faculty or research mentors Modeling self-advocacy

Education/Career Development

Helping mentees who are first generation to explain research pathways to parents

Thinking outside of the box - realizing other options

Having $2^{\text {nd }}$ thoughts about major

Student Life (Opportunities, Support, Problem-Solving) 
Talking about social/recreational opportunities on campus (e.g., clubs, sports) Discussing community engagement and service opportunities
Helping with work/school/personal life balance Presence! Just being there and available to talk Offering practical advice for dealing with obstacles or frustrations

Being a friendly familiar face

Being a confidant

Facilitating problem-solving or finding guidance

Being a willing advocate

Helping with boundaries and when to say no

Recognizing diversity and differences

Guiding students to opportunities

Providing information about jobs

Helping cope with set-backs or rejection

when applying for scholarships or

opportunities

Helping overcome fear and anxiety over

academic situations

Supporting with self-care

Connecting with resources on campus

Offering encouragement

Getting to campus (travel issues)

Finding extracurricular activities

Being a friend!

\section{Implementation of peer mentoring component}

Implementation of the BUILD EXITO peer mentoring model is based on recommended practices for program operations (Collier, 2015). The core elements of the program—recruiting, hiring, training, matching, supervising and monitoring of mentors - are described briefly below, with specific references to activities in the first year of the project. Strategies for the ongoing evaluation of the program also are noted.

Recruiting mentors. Several priorities were established for the selection of EXITO peer mentors, including a preference for backgrounds and experiences aligning with program goals as well as personal qualities generally associated with successful mentoring (Terrion \& Leonard, 2007). In the first year of the program, we sought advanced and academically successful students (seniors) from diverse backgrounds who had experience in research settings. We also wanted mentors who could interact with scholars in an engaging, positive, and supportive manner. Given this particular profile, we focused recruitment efforts on attracting applicants from other programs promoting science equity and inclusion for traditionally underrepresented students (e.g., McNair Scholars, Louis Stokes Alliance for Minority Participation, Bridges to Baccalaureate). We also conducted outreach through PSU's Multicultural Student Services, posted to listservs and social media, and sent personalized emails to students recommended by faculty. We also used a mailing 
list of students that had contacted BUILD EXITO and expressed interest in participating in the program but were ineligible due to their more advanced status.

Hiring mentors. Peer mentor applicants completed an online application that included questions about educational background, transfer student experience, research experience, prior mentoring and advising, leadership, and academic honors. Applicants completed three short (300 word) essays on (a) academic and career goals related to interest in biomedical, behavioral or social science research career pathways; (b) ways in which their own personal histories prepared them to support students from diverse and underrepresented backgrounds; and (c) what skills and qualities they possessed that would help them be successful in the role of a mentor for BUILD EXITO. Applicants also provided a letter of recommendation and a transcript. We received 25 applications, and 19 were selected for 20 minute interviews that included questions on motivations to be a mentor, experience with research, skills for successful mentoring, and experience helping other students. We also asked applicants to describe how they had "bounced back" from a setback, learned from a mistake, and dealt with overcommitting. Using a scoring rubric for the application and interview, we hired 15 peer mentors as hourly student employees. Each peer mentor was expected to work 10 hours per week during the academic year.

Training mentors. The new peer mentors received 8.5 hours of pre-match training, divided into three sessions. Training included the following topics: EXITO project overview; overview of the EXITO mentoring program; mentor policies and guidelines; introduction to the EXITO Mentoring Support Network (EMSN); mentoring roles; aligning expectations; effective communication; career directions; and ethical situations. Peer mentors who were unable to attend the trainings due to class scheduling conflicts received one-on-one training. Training materials for peer mentors were adapted from a widely used curriculum, designed for training academic research mentors of undergraduates in STEM and biomedical disciplines, entitled Entering Mentoring (Pfund, Branchaw \& Handelsman, 2015). Three members of the BUILD EXITO leadership team attended a train-the-trainer workshop through the National Research Mentoring Network (NRMN) to prepare them to use the training curriculum. In addition to the Entering Mentoring Curriculum, training activities on responding to difficult mentoring situations were adapted from the PSU University Studies Peer Mentoring program. After matching, additional training consisted of a two-hour session during spring term of the academic year. This training included debriefing mentoring successes and challenges as well as preparation of mentors to have an end-of-year conversation with each of their mentees. In subsequent years of the project, we also elicited their suggestions for improving the program and modifying the mentoring model, so that EXITO scholars eventually could serve as peer mentors to incoming cohorts.

Matching mentors. Each peer mentor was matched with between three and five EXITO scholars. Peer mentors from PSU were matched with scholars from PSU and from the partnering community colleges; the other 4-year partner institutions hired and matched peer mentors for their own campuses. Matching was based on several factors, including academic discipline, research interests, and transfer student experience. In addition, at PSU, we held a "speed" acquaintance event, in which pairs of peer mentors and scholars had 5 minutes to speak one-toone, with everyone rotating through 5 different pairings. At the end of the event, we asked participants to indicate three mentors/scholars they particularly enjoyed meeting.

Supervising mentors. The EXITO mentoring coordinator supervised peer mentors. As a baseline, peer mentors were expected to meet at least every other week one-to-one with each of their 
scholars. Contacts with scholars at partner campuses could occur via videoconferencing, phone or email. Although not required, a strategy that proved very effective with several peer mentors was emailing scholars weekly. Peer mentors also were encouraged to participate in EXITO scholar enrichment activities offered regularly throughout the academic year. In addition, peer mentors assisted with other program functions that involved student contact, such as outreach and recruitment activities. In particular, peer mentors contacted students who had started but not finished applications to provide individual encouragement and coaching on completing the application process (e.g., Castleman \& Page, 2015).

Monitoring matches. A central tenet of the BUILD EXITO mentoring program is that making good matches is not sufficient; each mentoring relationship should have ongoing monitoring and support from the professional program coordinator (Keller, Logan, Zell, Lindwall, Beals, 2016). An innovative online platform, the EXITO Mentoring Support Network (EMSN), supported by America Learns, is used for maintaining regular communication with all mentors and scholars in the program. Each participant has an individual ESMN account with an associated profile that contains relevant characteristics, such as personal demographics, program status, institutional affiliation, and academic discipline. The profile also identifies each mentor matched to a particular scholar, and vice versa (e.g., a mentor may have multiple scholars). On a monthly basis, each participant (both mentor and scholar) receives a scheduled email prompt to enter the EMSN system. On the landing page, the participant sees general program announcements and news updates. After logging in, the participant responds to a set of questions about each mentoring relationship. Certain consistent questions elicit basic tracking information about the nature and development of the mentoring relationship, such as the amount of hours of contact, the types of mentoring activities, and the quality of the relationship. Other questions can be customized to obtain specific information about the mentoring relationship or topics relevant for program improvement. Use of the EMSN system is an efficient means of tracking and monitoring the large number of EXITO mentoring relationships across multiple, widely dispersed institutions. The questions are designed to generate information about whether particular relationships are positive and productive or whether they are struggling and need support. EMSN allows the mentoring program coordinator to view and respond directly back to comments and questions noted in participant logs. Thus, it is easy for the program coordinator to suggest strategies and solutions and provide ongoing encouragement, advice, and guidance as needed. In addition, each account compiles a cumulative record of completed logs, so participants have access to a historical record of their relationships.

Closing matches. In spring term of the academic year, peer mentors were trained on match closure procedures and were provided with an "End of Year Conversation Guide." Goals for the end-of-year mentoring conversation were to: (a) celebrate the relationship; (b) reflect on what did and did not go well; (c) work with the scholar to help prepare them to get the most out of their future mentoring relationships; and (d) to discuss expectations for the future after the closure of the formal peer mentoring relationship. The guide included a number of reflection questions designed for both the peer mentor and the scholar to complete prior to their final meeting.

Evaluating the program. The BUILD EXITO mentoring program is subject to extensive evaluation. Each BUILD site participates in the cross-site, consortium-wide evaluation 
conducted by the UCLA Coordination and Evaluation Center and also carries out a site-specific evaluation. All evaluation activities are designed to: (a) measure the success of EXITO in meeting BUILD hallmarks for success; (b) engage EXITO faculty and staff in ongoing process improvement; and (c) contribute to knowledge on initiatives that further the success of underrepresented students in biomedical fields. A mixed-methods approach involves use of surveys, interviews, and institutional records to obtain data regarding the experience of scholars and mentors.

With respect to the mentoring program, the regular and customized EMSN log questions permit the identification of participant needs, relationship trends, and program issues. Specifically, both mentors and scholars report on their amount of contact, the nature of their activities, and the quality of their communication, use of time, and overall relationship. The profiles make it possible to compile and analyze the data in the aggregate or for specific subgroups to yield program insights. Thus, the mentoring program gains valuable real-time feedback that can be used to address emerging concerns or to promote quality improvement.

In addition, the EMSN system is useful for required program evaluation and reporting purposes. Data from the logs is consistent and centralized. Thus, it can be used to verify and summarize the nature and extent of mentoring activities across the multiple institutional sites. Again, the profiles permit comparisons and analyses based on a variety of relevant personal characteristics and program factors. The site-specific evaluation includes a quasi-experimental design to compare EXITO program scholars to other students on dimensions such as academic performance, self-efficacy, science identity, research productivity, and educational plans. The annual scholar assessment for the evaluation also includes established measures of mentoring relationship quality. Finally, to gain additional insights about the peer mentoring component of the program, several focus groups have been conducted with peer mentors and scholars.

\section{Peer mentor program challenges and changes}

Challenges. As intended, EMSN logs, focus groups, interviews, and staff observations generated a wealth of feedback regarding the first year of BUILD EXITO peer mentoring program implementation. Overall, peer mentors and scholars tended to report positive mentoring interactions and valued their participation in the program. However, several important challenges were identified, and these are noted briefly below.

- It was difficult for a single mentoring coordinator with multiple program responsibilities to train and supervise such a large number of peer mentors.

- Peer mentors and scholars often had difficulties arranging meetings and reported that trying to schedule their contacts was time-consuming and frustrating.

- Cross-institutional mentoring relationships (i.e., peer mentor and scholar at different institutions), particularly those over great distances, had problems connecting due to communications challenges (e.g., different time zones, unreliable internet) and the inability to meet in person.

- Because BUILD EXITO was a new program and many components were just being solidified, including the curriculum and the sequence of milestones and expectations for scholars, peer mentors struggled with understanding program features and meshing their role with the program. 
- The three-mentor model created some confusion regarding the specific role and purpose of the peer mentor and raised the possibility of overlap across mentoring relationships.

- Scholars sometimes felt overtaxed in trying to keep appointments and maintain relationships with three mentors.

Changes. Entering the second year of program implementation, several modifications were made to the peer mentoring component of the BUILD EXITO program to address the challenges identified and to accommodate a new and larger cohort of scholars. The most significant change was to integrate the peer mentoring with the weekly enrichment workshops for EXITO scholars. Peer mentors now work closely with a faculty member to organize and deliver the workshop sessions, which all scholars are expected to attend at a consistent time every week in the EXITO Center. This approach has some distinct advantages.

For example, mentors can count on having regular contact with their scholars without needing to spend time arranging appointments. In addition, peer mentors have a more clearly defined role through their involvement with the workshop content. With the structure provided by the workshop, they can bring their student perspective to the topics presented and then continue the conversations and activities with their mentees after the sessions. For scholars, too, the mentoring relationship is built in the context of an activity they already would be doing, so it doesn't seem like extra time is required for "one more" mentoring relationship. Given that much of the mentoring now occurs in this routine group structure, each mentor is matched to a larger number of scholars (10-12). As a result, fewer peer mentors were hired and the supervisory burden was reduced.

Each peer mentor has half of their scholars at PSU, and the other half at one of the community colleges. Matches were made at the time of the scholar orientation, so the mentoring relationship could begin to develop over the summer. In addition, scholars from partner community colleges (including American Samoa and Northern Mariana) were able to meet their mentors in person at the orientation. In the new framework, peer mentors are still expected to have individual, one-toone contact with their scholars a few times each term in addition to weekly check-ins by email or text message.

\section{Conclusion}

Undergraduates from backgrounds traditionally underrepresented in higher education can benefit from a convoy of support on the challenging pathway to become a scientist (De Janasz \& Sullivan, 2004). Multiple domains of support can be provided through formal mentoring relationships (Nora \& Crisp, 2007). Near-peer mentors can make several distinctive contributions by serving as role models, connecting students to campus life, and sharing the lessons they have learned traveling the same pathway (Hill \& Reddy, 2007; Wallace, Abel \& Ropers-Huilman, 2000; Ward, Thomas \& Disch, 2012; Zaniewski \& Reinholz, 2016). For this reason, the BUILD EXITO project intentionally incorporates peer mentoring into its multiplementor program model. BUILD EXITO peer mentoring serves as an example for implementation of recommended and innovative program practices. The rigorous evaluation of the mentoring program currently underway has the potential to yield valuable insights for programs supporting diversity in the sciences. 


\section{References}

Bangera, G., \& Brownell, S. E. (2014). Course-based undergraduate research experiences can make scientific research more inclusive. CBE-Life Sciences Education, 13(4), 602-606.

https://doi.org/10.1187/cbe.14-06-0099

Building Infrastructure Leading to Diversity (BUILD) Initiative (2016, April 15). Retrieved from https://www.nigms.nih.gov/training/dpc/pages/build.aspx

Campbell, T. A., \& Campbell, D. E. (1997). Faculty/student mentor program: Effects on academic performance and retention. Research in Higher Education, 38(6), 727-742. https://doi.org/10.1023/A:1024911904627

Castleman, B. L., \& Page, L. C. (2014). Summer nudging: Can personalized text messages and peer mentor outreach increase college going among low-income high school graduates? Journal of Economic Behavior \& Organization, 115, 144-160. https://doi.org/10.1016/j.jebo.2014.12.008

Chang, M. J., Sharkness, J., Hurtado, S., \& Newman, C. B. (2014). What matters in college for retaining aspiring scientists and engineers from underrepresented racial groups. Journal of Research in Science Teaching, 51(5), 555-580. https://doi.org/10.1002/tea.21146

Chemers, M. M., Zurbriggen, E. L., Syed, M., Goza, B. K., \& Bearman, S. (2011). The role of efficacy and identity in science career commitment among underrepresented minority students. Journal of Social Issues, 67(3), 469-491. https://doi.org/10.1111/j.1540-4560.2011.01710.x

Collier, P. J. (2015). Developing effective student peer mentoring programs: A practitioner's guide to program design, delivery, evaluation, and training. Sterling, VA: Stylus Publishing.

De Janasz, S. C., \& Sullivan, S. E. (2004). Multiple mentoring in academe: Developing the professorial network. Journal of Vocational Behavior, 64, 263-283.

https://doi.org/10.1016/j.jvb.2002.07.001

Department of Health and Human Services (2013, December 19). RFA-RM-13-016: NIH Building Infrastructure Leading to Diversity (BUILD) Initiative (U54). Retrieved from: http://grants.nih.gov/grants/guide/rfa-files/RFA-RM-13-016.html

Enhancing the diversity of the NIH-funded workforce (2016, July 26). Retrieved from: https://www.nigms.nih.gov/training/dpc/Pages/default.aspx

Gazley, J. L., Remich, R., Naffziger-Hirsch, M. E., Keller, J., Campbell, P. B., \& McGee, R. (2014). Journal of Research in Science Teaching, 51(8), 1021-1048.

https://doi.org/10.1002/tea.21164

Ginther, D. K., Schaffer, W. T., Schnell, J., Masimore, B., Liu, F., Haak, L. L., \& Kington, R. (2011). Race, ethnicity, and NIH research awards. Science, 333(6045), 1015-1019.

https://doi.org/10.1126/science.1196783 
Guise, J. M., Geller, S., Regensteiner, J. G., Raymond, N., \& Nagel, J. (2016). Team mentoring for interdisciplinary team science: Lessons from K12 scholars and directors. Academic Medicine, 92(2), 214-221.

Higgins, M. C., \& Thomas, D. A. (2001). Constellations and careers: Toward understanding the effects of multiple developmental relationships. Journal of Organizational Behavior, 22, 223247. https://doi.org/10.1002/job.66

Hill, R., \& Reddy, P. (2007). Undergraduate peer mentoring: An investigation into processes, activities and outcomes. Psychology Learning and Teaching, 6, 98-103.

https://doi.org/10.2304/plat.2007.6.2.98

Hunter, A., Laursen, S. L., Seymour, E. (2007). Becoming a scientist: The role of undergraduate research in students' cognitive, personal, and professional development. Science Education, 91(1), 36-74. https://doi.org/10.1002/sce.20173

Hurtado, S., Han, J. C., Saenz, V. B., Espinosa, L. L., Cabrera, N. L., \& Cerna, O. S. (2007). Predicting the transition and adjustment to college: Biomedical and behavioral science aspirants' and minority students' first year of college. Research in Higher Education, 48(7), 841-887. https://doi.org/10.1007/s11162-007-9051-X

Keller, T. E., Collier, P. J., Blakeslee, J. E., Logan, K., McCracken, K., \& Morris, C. (2014). Early career mentoring for translational researchers: Mentee perspectives on challenges and issues. Teaching and Learning in Medicine: An International Journal, 26(3), 211-216. https://doi.org/10.1080/10401334.2014.883983

Keller, T. E., Logan, K., Zell, A., Lindwall, J., \& Beals, C. (2016). Monitoring and supporting a multi-faceted, multi-institutional student mentoring program. In Dominquez, N. \& Gandert, Y. (Eds.) $9^{\text {th }}$ Annual Mentoring Conference Proceedings: Developmental Networks-The Power of Mentoring and Coaching. Albuquerque, NM: University of New Mexico.

Kendricks, K. D., Nedunuri, K. V., \& Arment, A. R. (2013). Minority student perceptions of the impact of mentoring to enhance academic performance in STEM disciplines. Journal of STEM Education: Innovations and Research, 14(2), 38-46. Retrieved from http://jstem.org/index.php?journal=JSTEM

Kuh, G. D., Kinzie, J., Buckley, J. A., Bridges, B. K., \& Hayek, J. C. (2006). What matters to student success: A review of the literature. Washington, D.C.: National Postsecondary Education Cooperative of National Center for Education Statistics Institute of Education Sciences. Retrieved from https://nces.ed.gov/npec/pdf/Kuh_Team_Report.pdf

Linn, M. C., Palmer, E., Baranger, A., Gerard, E., \& Stone, E. (2015). Undergraduate research experiences: Impacts and opportunities. Science, 347(6222), 1261757.

https://doi.org/10.1126/science.1261757 
Lopatto, D. (2007). Undergraduate research experiences support science career decisions and active learning. CBE-Life Sciences Education, 6(4), 297-306. https://doi.org/10.1187/cbe.07-06$\underline{0039}$

McGee, R., Saran, S., \& Krulwich, T. A. (2012). Diversity in the biomedical research workforce: Developing talent. Mount Sinai Journal of Medicine, 79(3), 397-411.

https://doi.org/10.1002/msj.21310

Mitchell, D. A, \& Lassiter, S. A. (2006). Addressing health care disparities and increasing workforce diversity: The next step for the dental, medical, and public health professions. American Journal of Public Health, 96 (12), 2093-2097. https://doi.org/10.2105/AJPH.2005.082818

Nora, A., \& Crisp, G. (2007). Mentoring students: Conceptualizing and validating the multidimensions of a support system. Journal of College Student Retention, 9(3), 337-356. https://doi.org/10.2190/CS.9.3.e

Packard, B. W., Walsh, L., \& Seidenberg, S. (2004). Will that be one mentor or two? A crosssectional study of women's mentoring during college. Mentoring and Tutoring: Partnership in Learning, 12(1), 71-85. https://doi.org/10.1080/1361126042000183039

Pfund C, Branchaw, J., \& Handelsman, J. (2015). Entering Mentoring Version 2. New York, NY: W.H. Freeman \& Co.

Reason, R. D. (2009). An examination of persistence research through the lens of a comprehensive conceptual framework. Journal of College Student Development, 50(6), 659-682. https://doi.org/10.1353/csd.0.0098

Richardson, D. M., Keller, T. E., Wolf, D., Zell, A., Morris, C., \& Crespo, C. (2016). BUILD EXITO: Supporting diversity in health-focused research across U.S. Pacific states and territories. Manuscript submitted for publication.

Russell, S. H., Hancock, M. P., McCullough, J. (2007). Benefits of undergraduate research experiences. Science, 316(5824), 548-549. https://doi.org/10.1126/science.1140384

Schreiner, L. A., Noel, P., Anderson, E. C., \& Cantwell, L. (2011). The impact of faculty and staff on high-risk college student persistence. Journal of College Student Development, 52(3), 321-338. https://doi.org/10.1353/csd.2011.0044

Shanahan, J. O., Ackley-Holbrook, E., Hall, E., Stewart, Kearsley, S., Walkington, H. (2015). Ten salient practices of undergraduate research mentors: A review of the literature. Mentoring \& Tutoring: Partnership in Learning, 23(5), 359-376. https://doi.org/10.1080/13611267.2015.1126162 
Shaw, K., Holbrook, A., \& Bourke, S. (2013). Student experience of final-year undergraduate research projects: an exploration of 'research preparedness'. Studies in Higher Education, 38(5), 711-727. https://doi.org/10.1080/03075079.2011.592937

Syed, M., Azmitia, M., \& Cooper, C. R. (2011). Identity and academic success among underrepresented ethnic minorities: An interdisciplinary review and integration. Journal of Social Issues, 67(3), 442-468. https://doi.org/10.1111/j.1540-4560.2011.01709.x

Terrion, J. L., \& Leonard, D. (2007). A taxonomy of the characteristics of student peer mentors in higher education: Findings from a literature review. Mentoring \& Tutoring, 15(2), 149-164. https://doi.org/10.1080/13611260601086311

Thiry, H., \& Laursen, S. L. (2011). The role of student-advisor interactions in apprenticing undergraduate researchers into a scientific community of practice. Journal of Science Education and Technology, 20(6), 771-784. https://doi.org/10.1007/s10956-010-9271-2

Valantine, H. A., \& Collins, F. S. (2015). National Institutes of Health addresses the science of diversity. Proceedings of the National Academy of Sciences, 112(40), 12240-12242.

van Emmerik, I. J. H. (2004). The more you can get the better: Mentoring constellations and intrinsic career success. Career Development International, 9(6), 578-594.

https://doi.org/10.1108/13620430410559160

Wallace, D., Abel, R., \& Ropers-Huilman, B. (2000). Clearing a path for success:

Deconstructing borders through undergraduate mentoring. The Review of Higher Education, 24(1), 87-102. https://doi.org/10.1353/rhe.2000.0026

Weaver G.C., Russell C.B., \& Wink D.J. (2008). Inquiry-based and research-based laboratory pedagogies in undergraduate science. Nature Chemical Biology, 4(10), 577-580.

https://doi.org/10.1038/nchembio1008-577

Zaniewski, A. M., \& Reinholz, D. (2016). Increasing STEM success: A near-peer mentoring program in the physical sciences. International Journal of STEM Education, 3(1), 14.

https://doi.org/10.1186/s40594-016-0043-2

\section{Acknowledgements}

This article and the project it describes were supported by awards from the National Institutes of Health (UL1MD009596, RL5MD009591, UL1GM118964, RL5GM118963). The content is solely the responsibility of the authors and does not necessarily represent the official views of the National Institutes of Health. 


\section{Author information}

* Thomas E. Keller is the Duncan \& Cindy Campbell Professor in the School of Social Work at Portland State University. He also is the Director of the Center for Interdisciplinary Mentoring Research and the Co-Principal Investigator for the BUILD EXITO project.

Thomas E. Keller

School of Social Work

Portland State University

P.O. Box 751

Portland, OR 97207

E-mail: kellert@pdx.edu

Telephone: 503-725-8205

Kay Logan is the Coordinator of the Center for Interdisciplinary Mentoring Research and the Coordinator for the mentoring programs in the BUILD EXITO project.

Kay Logan

Center for Interdisciplinary Mentoring Research

Portland State University

P.O. Box 751

Portland, OR 97207

E-mail: log@pdx.edu

Telephone: 503-725-9680

Jennifer Lindwall is the Communications Director for the BUILD EXITO project and a doctoral student in Applied Psychology at Portland State University.

Jennifer Lindwall

Center for Interdisciplinary Mentoring Research

Portland State University

P.O. Box 751

Portland, OR 97207

E-mail: lindwall@pdx.edu

Caitlyn Beals is a Program Coordinator for the BUILD EXITO project who supports the mentoring program.

Caitlyn Beals

Center for Interdisciplinary Mentoring Research

Portland State University

P.O. Box 751

Portland, OR 97207

E-mail: cbeals@pdx.edu

Telephone: 503-725-9281

*Corresponding author 